\title{
JOVENS EMPREENDEDORES ESTÃO PREPARADOS PARA EMPREENDER EM EMPRESAS DE BASE TECNOLÓGICA? ${ }^{1}$
}

\section{ARE ENTERPRISING YOUTHS PREPARED TO UNDERTAKE IN HIGH-TECH COMPANIES?}

\author{
Francisco Ricardo Bezerra Fonsêca ${ }^{2}$ \\ Sérgio Benício C. de Mello ${ }^{3}$ \\ Maria Christianni Coutinho Marçal ${ }^{4}$ \\ Maria Iraê de Souza Correa ${ }^{5}$
}

\begin{abstract}
Resumo: O empreendedorismo se apresenta (teórica e praticamente) como um fenômeno abrangente capaz de fomentar uma infinidade de questões frente à realidade dinâmica e complexa dos negócios contemporâneos em que está inserido. Este artigo objetiva explorar os fatores que influenciam a intenção de empreender dos estudantes egressos e concluintes de cursos de base tecnológica de uma grande universidade brasileira. $\mathrm{O}$ estudo foi realizado por meio de uma abordagem qualitativa onde foram efetuadas entrevistas em profundidade. No plano analítico foi utilizada análise de conteúdo, que compreende o processo de transcrição dos relatos dos entrevistados, codificação dos conteúdos e interpretação de seus significados. A categoria vontade (i.e. ato do ser humano de escolher livremente praticar ou não certos atos) foi apontado como um dos fatores fundamentais na influência da intenção do ato de empreender. O perfil auto-percebido dos empreendedores, que corrobora com a idéia de âncora de carreira, embasamento teórico do estudo, foi evidenciado como um achado empírico relevante onde a âncora de carreira gerencial revelou-se com maior freqüência.
\end{abstract}

Palavras-Chave: Empreendedorismo, Âncoras de carreira, Intenções de empreender

Abstract: Entrepreneurship (theoretical and practically) as a phenomenon is capable of fomenting an infinity of issues regarding the dynamic and complex reality of contemporary businesses. This paper aims at to explore the factors that influence the intention of becoming an entrepreneur by alumini and senior students of a major Brazilian University undertaking high-tech degrees. This qualitative study was accomplished through in-depth interviews. In the analytical scope, a content analysis was undertaken comprehending the process of transcription of the interviewees' reports, codification of contents and interpretation of their meanings. The category will (i.e., the human act of choosing freely to practice or not certain actions) poised as one of the fundamental factors influencing the intentional act of enterprising. The entrepreneurs' self-perceived profile, which corroborates with the idea of career anchor (major theory used in this study), was evidenced as a relevant empiric discovery while the anchor of managerial career was revealed more frequently.

Key-words: Entrepreneurship, Career anchors, Enterprising intentions

\footnotetext{
${ }^{1}$ Artigo Recebido em 06.08.2008 . Revisado por pares em 12.01.2009 . Recomendado em 02.02.2009 por Denise Del Pra Netto Machado (editora). Publicado em 02.03.2009.

Organização Responsável pelo periódico: Universidade regional de Blumenau - FURB - www.furb.br/rn
}

\footnotetext{
${ }^{2}$ Professor da Universidade Federal do Pernambuco - ricardofonseca01@gmail.com

${ }^{3}$ Professor da Universidade Federal do Pernambuco - sergio.benicio@pesquisador.cnpq.br

${ }^{4}$ Professora da Faculdade Maurício de Nassau e da Faculdade Boa Viagem - chrismarcal@hotmail.com

${ }^{5}$ Professor da Universidade Federal do Pernambuco - mariairae@ hotmail.com
} 


\section{INTRODUÇÃO}

No Brasil a preocupação com a criação de empresas e com a redução do alto índice de falência de novos negócios, pode ser a razão pela qual o fenômeno empreendedor tenha assumido importância no âmbito do governo, das entidades de classe, de instituições de apoio e da própria academia (FILION, 1999; PREVIDELLI et al., 2001). Vivemos um contexto em que se reconhece a importância do empreendedorismo para o desenvolvimento econômico, ao mesmo tempo em que se revela um desconhecimento acerca da pessoa do empreendedor. As iniciativas de começar uma atividade produtiva no país divergem daquelas citadas pela literatura de empreendedorismo.

O esforço intencional de abrir ou expandir um empreendimento é atribuído à busca por geração de riquezas e crescimento econômico, em contraste com os mecanismos de substituição do emprego, ou a tentativa de evitar esquemas aviltadores de relações de trabalho tão presentes na realidade nacional (GITAHY et al., 1998; LEITE e RIZEK, 1999; POCHMANN, 2001). Desta forma, embora nos últimos dez anos tenha surgido crescente e significativo interesse pelo empreendedorismo como fenômeno multidimensional que modifica as condições correntes do mercado pela introdução de algo novo e diferente em resposta a necessidades identificadas no ambiente organizacional (DRUCKER, 1987; FILION, 1999; PREVIDELLI et al., 2001), a pessoa do empreendedor com suas peculiaridades essenciais tem carecido de maior atenção por parte dos estudiosos sobre o tema (KETS DE VRIES, 1995; PHILIPSEN, 1998, KISFALVI, 2002).

O empreendedorismo tecnológico surge neste cenário como oportunidade e objeto de fomento em alta escala no qual não há uma clara identificação das forças motrizes do ato de empreender. Esta investigação visa compreender a influência de alguns fatores relacionados às intenções atreladas ao ato de empreender assim como à orientação profissional do indivíduo, denominados "âncoras de carreira" (SCHEIN, 1978), para a formação da intenção de direcionar a carreira profissional no sentido de empreender novos negócios. Dessa forma, o presente estudo tem como objetivo de trazer luz às seguintes questões: Quais são os fatores relacionados à intenção de empreender dos jovens empreendedores concluintes e egressos dos cursos de base tecnológica de uma grande Universidade Brasileira? Será que os cursos de base tecnológica são indutores da vontade empreendedora?

No ímpeto de situar o leitor quanto à lógica de construção do artigo, esse estudo encontra-se disposto da seguinte maneira: 1) primeiro é apresentado o aporte teórico que serviu de base para investigarmos o fenômeno em questão. Iniciamos a segunda seção do artigo definindo o empreendedor, logo após as intenções de empreender, os principais tipos de carreira, as âncoras de carreira e, por fim, o contexto situacional do moderador. A terceira seção traz à baila as questões metodológicas desse estudo. Na quarta seção são apresentados e discutidos os resultados da investigação. Por fim, têm-se as conclusões decorridas desses resultados.

\section{O EMPREENDEDOR}

Ainda que não exista um consenso teórico ou um modelo capaz de quantificar o desenvolvimento econômico a partir do Empreendedorismo, pode-se perceber que este fenômeno tem causado impacto sobre a atividade econômica atual (FILION, 1999). É razoável admitir que o campo do Empreendedorismo carece, e bastante, de contribuições da própria pesquisa. Nos últimos 10 (dez) anos, tem-se constatado um crescente interesse nesse campo de estudo (i.e., pode-se verificar a criação de cursos e a adoção de disciplinas regulares em empreendedorismo em diversas universidades). Diante disso, é fundamental compreender 
esse fenômeno como um elemento bastante útil à compreensão e modificação do desenvolvimento econômico.

Embora na literatura sobre empreendedorismo, exista muita confusão a respeito da definição do termo "empreendedor" (FILION, 1999), pode-se aceitar o empreendedorismo como um processo de mudança que atinge as condições correntes do mercado através da introdução de algo novo ou diferente em resposta a necessidades percebidas (SMILOR, 1997). Neste contexto, o empreendedor surge como uma figura que cria novas oportunidades de mercado.

\subsection{Intenções Empreendedoras}

O termo empreendedorismo pode ser definido como o processo de "emergência" na criação de organizações (GARTNER, 1988; GARTNER et al., 1992). Isto significa que é visto como um processo engendrado por indivíduos para possibilitar que uma organização venha a existir, um "tornar-se" mais do que um "ser". Sendo assim, a compreensão das intenções empreendedoras é central para o entendimento deste processo, pois constituem as fundações para a abertura de novas organizações (KRUEGER, 1993). Como o processo empreendedor ocorre ao longo do tempo (GARTNER et al., 1994), as intenções empreendedoras podem ser vistas como o primeiro passo deste processo evolutivo, de longo prazo, de criação de um novo negócio.

As intenções empreendedoras correspondem a um "estado de espírito" que direciona a atenção, experiência e ação de um indivíduo para objetivo de fundar um negócio (BIRD, 1988), bem como abrangem o comprometimento deste indivíduo com a abertura deste novo negócio (KRUEGER, 1993). Além disso, as intenções em direção a um comportamento vêm sendo rotineiramente demonstradas como o melhor prognosticador avulso daquele comportamento (FISHBEIN e AJZEN, 1975). Sem intenção, a ação é improvável. Por isso, as intenções empreendedoras são cruciais para o entendimento de todo o processo empreendedor, por servirem como condutor inicial para ações e eventos subseqüentes relacionados com a abertura de novos negócios (BIRD, 1988; 1992; BOYD e VOZIKIS, 1994; CRANT, 1996; JENKINS e JOHNSON, 1997; KATZ e GARTNER, 1988; KRUEGER, 1993; KRUEGER e CARSRUD, 1993).

Fatores que podem afetar as intenções de um indivíduo em fundar um negócio incluem as características do indivíduo assim como as características da situação (REYNOLDS, 1991). Dado que nem todos os indivíduos tornar-se-ão empreendedores sob circunstâncias externas comparáveis, os atributos psicológicos do indivíduo constituem parte integrante da pesquisa em empreendedorismo (JOHNSON, 1990; STEWART et al., 1998).

Desta forma, o processo das intenções empreendedoras pode começar com as necessidades, valores, vontades, hábitos e crenças pessoais de um indivíduo (BIRD, 1988). Indivíduos que possuem intenções de criar uma organização têm certas atitudes, interesses, valores e talentos precursores, relacionados com empreendedorismo, e que formam parte do conteúdo de suas intenções empreendedoras. Estes precursores individuais não estão, no entanto, distinguidos de forma clara na literatura. Scheinberg e Mac Millian (1988), por exemplo, mostram que a necessidade de aceitação, a instrumentalidade percebida da riqueza, o grau de associação, a necessidade de desenvolvimento pessoal, a necessidade de independência e a necessidade de libertação conduzem os indivíduos em direção à formação de novas empresas.

Estes fatores motivacionais, contudo, nem sempre se sustentam em outros estudos (STEWART et al., 1998). Não há uma orientação única que explique a propensão individual em direção a uma carreira empreendedora (VESPER, 1980). Alguns iniciam um negócio porque apreciam desenvolver uma nova tecnologia; outros o fazem por encontrarem prazer na 
construção e na propriedade de sua própria empresa. Outros, ainda, gostam de iniciar novos empreendimentos, mas têm aversão a gerenciá-los.

Fatores situacionais, como limitações de tempo, dificuldade de tarefas e influência de outras pessoas por meio de pressão social também influenciam as intenções empreendedoras (AJZEN, 1985,1987; BOYD; VOZIKIS, 1994; TUBBS e EKEBERG, 1991). Por exemplo, Dyer (1994) argumenta que carreiras empreendedoras são lançadas quando há uma carência de oportunidades de emprego nas organizações existentes. Fatores exógenos, portanto, também influenciam as atitudes de um indivíduo em direção ao empreendedorismo (KRUEGER, 1993).

\subsection{Principais tipos de carreira}

As possibilidades e trajetórias profissionais são múltiplas, podendo ser agrupadas em quatro grandes tipos, a saber: burocrático, profissional, empreendedor, sóciopolítico. Cada um desses tipos não só recupera uma tarefa precisa, mas indica também uma lógica no caminho a seguir, a natureza das trajetórias profissionais e o sistema de recompensas a ele associado (CHANLAT, 1995).

A carreira do tipo burocrático, como seu nome indica, remete às estruturas burocráticas da organização que pode oferecer avanço dentro de uma carreira que está estritamente dentro da pirâmide organizacional. Em cada nível concede-se certa responsabilidade, certo salário e vantagens sociais formalmente definidas. A antiguidade e os concursos são geralmente as bases da seleção, do recrutamento e da promoção. Historicamente associada à grande empresa oligopolista ou monopolista e ao seu desenvolvimento, este tipo de carreira parece, pouco adaptado à nova ordem, à concorrência internacional, às mudanças tecnológicas e ao apelo à flexibilidade, que minam pouco a pouco as estruturas burocráticas.

A carreira do tipo profissional baseia-se no monopólio de certo saber, da especialização, da profissão e da reputação. Ela não é uma carreira de tipo vertical, como é, forçosamente, a carreira burocrática. Seu avanço se faz, sobretudo, no interior da disciplina profissional, na medida em que o conhecimento e a experiências se acumulam. Um excesso de profissionalização notadamente em gestão, comporta certo risco, simultaneamente, para as sociedades, para as organizações e para os indivíduos, porque pode desenbocar num modo de gestão abstrato, formado por um grupo de especialistas geralmente distantes da realidade bem concreta da vida organizacional (CHANLAT, 1995).

A carreira do tipo empreendedor está ligada às atividades de uma empresa independente, traçadas por uma pessoa. Este tipo de carreira é, em geral, identificado com o empreendedor econômico. Hoje em dia, há uma concepção mais ampla desse tipo de carreira. Os artistas, os fundadores de empresas culturais, comunitárias ou beneficentes são aqui considerados sobre o mesmo título que os artesãos, os comerciantes e os patrões das pequenas e médias empresas.

Há alguns anos, a carreira de empreendedor, após ter sido eclipsada pela expansão das grandes organizações, parece ressurgir de maneira interessante. Fatores como as dificuldades do setor público, a crise do Estado-Previdência, as dispensas maciças em certas indústrias e a concorrência internacional parecem ter empurrado, por sua vez, os governos, as empresas e as sociedades para valorizarem novamente esse tipo de carreira. Mais arriscada do que os outros dois tipos de carreira, a carreira de empreendedor oferece, em caso de sucesso, recompensas materiais mais elevadas e, em certos casos, bem consideráveis. Tal êxito não será jamais alcançado por um burocrata ou por um profissional de alto nível, a menos que, bem entendido, ele próprio se transforme em um empreendedor. Isso não impede que numerosas pessoas defendam, cada vez mais, o desenvolvimento do espírito de empreendimento e as 
características associadas ao empreendedor - criatividade, inovação, gosto pelo risco, além de independência - nos cargos executivos e não-executivos das grandes empresas para melhorar o desempenho, nascendo assim, o empreendedorismo (CHANLAT, 1995).

Em certo sentido, o capital de relações desempenha um papel sobre os três tipos de carreira já apontados. A carreira não é mais unicamente o fruto da sorte, da criatividade, dos talentos, ou da competência, sendo também produto de um tecido de relações como nos indicam certos estudos clássicos sobre a maneira com que as pessoas se reconduzem ao emprego. O particular no tipo de carreira sóciopolítico é que nele o capital de relações domina largamente todo o resto. Em certas empresas, nas quais o caráter do clã é fortemente acentuado, ele substitui com vantagem o diploma, os concursos, a antiguidade e a competência profissional.

\section{3 Âncoras de carreira}

Intenções empreendedoras são influenciadas em um plano individual por convicções pessoais acerca das próprias características, convicções estas que encorajam a escolha de ocupações que se alinhem com o perfil auto-percebido. O conceito de âncora de carreira vem consubstanciar esta idéia (CROMIE, 1994; HOLLENBECK e WHITENER, 1988).

A partir de uma auto-imagem, construída e reconstruída em um processo contínuo, alicerçado em experiências profissionais diversas, que sedimentam uma percepção dos próprios talentos, necessidades e valores, é que se constituem as âncoras de carreira. Desta maneira, elas podem ser definidas como (1) competências e talentos auto-percebidos, baseados em sucessos efetivos numa variedade de ambientes de trabalho, (2) necessidades e motivações auto-percebidas baseadas em oportunidades de auto-diagnóstico em situações reais e em feedback de pares, e (3) atitudes e valores auto-percebidos, baseados em conflitos reais entre a própria pessoa e as normas e valores da organização empregadora e do ambiente de trabalho (SCHEIN,1978; KATZ, 1994).

Funcionando como um conjunto de forças motrizes e refreadoras que agem sobre as decisões e escolhas, as âncoras de carreira servem para guiar, refrear, estabilizar, integrar e redirecionar estas escolhas: um indivíduo tenderá a querer e a valorizar uma carreira na qual acredita ser competente, da mesma forma, dedicar-se-á a desenvolver suas competências nas áreas que deseja ou valoriza. A literatura aponta cinco principais tipos de âncoras de carreira (SCHEIN, 1978, 1996; BARTH, 1993; KATZ, 1994).

A Âncora de Segurança ou Estabilidade é predominante em indivíduos que, por serem avessos a risco, atam suas carreiras a organizações que lhes proporcionam segurança no emprego e estabilidade de carreira. Em geral, são rotulados como conformistas, pois para permanecerem na organização, socializam-se de acordo com os valores e normas vigentes e "confiam" à organização o desenvolvimento de suas próprias carreiras. Desta forma, indivíduos com uma forte âncora de segurança apresentam menor probabilidade de possuírem intenções empreendedoras, já que são menos dispostos a sair de suas zonas de conforto para assumir riscos. (SCHEIN, 1978; 1996; KOLVEREID, 1996; BARTH, 1993).

Indivíduos que desejam libertar-se de regras organizacionais e controles de supervisores têm como predominante à Âncora de Autonomia ou Independência. Procuram situações de trabalho nas quais se tornem livres de restrições organizacionais para que possam cuidar dos próprios interesses. Buscam condições que lhes permitam estabelecer seu ritmo e seu horário de trabalho, para ajustá-lo ao seu estilo de vida e aos seus hábitos pessoais. Independentes, preferem deixar empregos assalariados por carreiras que permitam que definam suas áreas de interesse e como as seguirão (SCHEIN, 1978, 1990; SMITH e MINER, 1983; KATZ, 1994; WOO et al., 1991; FELDMAN e BOLINO, 2000). 
Um outro perfil é aquele onde domina a Âncora Técnica ou Funcional. São indivíduos que organizam suas carreiras em torno de suas áreas de especialização, preferem movimentações de carreira que representem avanços dentro de sua área de expertise, são relutantes em direcionar para responsabilidades gerenciais, e apreciam desenvolver tecnologias. Se tiverem intenções de iniciar um negócio, este deve ser numa área afim ao seu campo de conhecimento técnico. (SCHEIN, 1978; ALLEN e KATZ, 1986; IGBARIA et al., 1991; BARTH, 1993)

A Âncora de Criatividade ou Inovação é preponderante naqueles indivíduos que têm uma necessidade de criar "algo novo", sendo similar à orientação empreendedora oportunista. São motivados a se tornarem auto-empregados pela chance de usarem suas habilidades e serem criativos, assim como de capitalizar numa boa idéia de negócio. Estão sempre tentando tocar novos tipos de projetos porque têm uma incansável propensão a novidades e desafios (SCHEIN, 1978; KATZ, 1994; SMITH e MINER, 1983; FELDMAN e BOLINO, 2000; BARTH, 1993).

Finalmente temos a Âncora Gerencial onde se situam indivíduos interessados na possibilidade de exercitar autoridade formal, poder e influência em alto grau e relacionar as realizações organizacionais aos seus próprios esforços. No geral, esses indivíduos, têm fortes competências analíticas, que os habilitam a identificar, analisar e resolver problemas sob condições de informação incompleta e incerteza. Devido às crescentes pressões competitivas e ao encolhimento das corporações, reduzem-se as oportunidades de promoção para os profissionais, de quem é esperado um comportamento empreendedor, flexível e responsivo às exigências de trabalho em mutação. Na medida em que os indivíduos ganham experiência em suas carreiras, um número cada vez maior direciona-se ao auto-emprego, ao invés de perseguir carreiras de longo prazo em uma só organização. Considerando que indivíduos que têm forte âncora gerencial possuem habilidades gerenciais ou capital humano genérico, transportável para diferentes tipos de negócios, e tipicamente almejam uma posição de alto nível numa empresa por medirem seu sucesso pela soma de suas responsabilidades e pela dimensão de suas tarefas de trabalho, aqueles que têm intenções empreendedoras serão indiferentes ao tipo de negócio a criar. (GOFFEE e SCASE, 1992; KANTER, 1989; NICHOLSON e WEST, 1988; BECKER, 1964).

\subsection{Contexto Situacional como Moderador}

Intenções empreendedoras estão também incrustadas no contexto sócio-cultural percebido (KRUEGER e BRAZEAL, 1994). Greenberger e Sexton (1988) propuseram um modelo empreendedor que incorpora tanto características individuais quanto influências ambientais. Eles postularam que decisões concernentes à criação de novos negócios constituem um processo interativo entre as características pessoais do indivíduo e sua interpretação de eventos notáveis no ambiente. O arcabouço conceitual de Gartner (1985) também retratou o processo de criação de novos empreendimentos como uma interação entre o ambiente, a organização, o indivíduo e seu comportamento empreendedor.

Segundo Herron e Sapienza (1992), as intenções individuais de fundar um novo negócio são mais diretamente influenciadas pela interação de suas habilidades pessoais e seu nível de insatisfação no trabalho. Especificamente, Dyer (1992) relata que experiências negativas de trabalho em grandes companhias convenceram muitos indivíduos de que uma carreira empreendedora seria mais satisfatória para eles. Dubini (1988), por sua vez, argumenta que empreendedores são, em sua maioria, indivíduos que se encontravam infelizes com suas condições prévias de trabalho e foram dirigidos a iniciar seus próprios negócios primordialmente por situações negativas como insatisfação com um trabalho anterior ou falta de outras oportunidades de carreira mais interessantes. Do mesmo modo, Gartner et al. (1989) 
também concluíram que um grupo de empreendedores iniciou seus negócios para escapar de seus empregos anteriores, por eles percebidos como oferecendo poucas recompensas em termos de salário, trabalho desafiador e oportunidades de promoção. Assim, o contexto situacional enfrentado por um indivíduo em seu trabalho atual tem efeito nas intenções de fundar um negócio (LEARNED, 1992).

O estudo de Greenhaus et al. (1978) também mostra que as intenções pessoais em procurar um tipo particular de emprego não são apenas uma função da atratividade da organização, mas também são influenciadas pela acessibilidade ou viabilidade da escolha. Portanto, limitações pessoais como dificuldades financeiras, incapacidade de levantar capital para um novo negócio, ou obrigações financeiras e pessoais pendentes restringem as intenções de um indivíduo de abrir um negócio.

\section{METODOLOGIA}

Este estudo correspondeu a uma pesquisa qualitativa, de caráter conclusivo-descritivo (MERriam, 1992). A base dos dados consistiu em entrevistas semi-estruturadas e em profundidade, realizadas com os estudantes e egressos dos cursos de base tecnológica de uma grande universidade brasileira que possuíam a intenção em ter um negócio próprio. Os critérios de escolha utilizados para selecionarmos os entrevistados desse estudo foram:

a) Ser concluinte ou egresso de algum dos 12 cursos de base tecnológica (Engenharia Cartográfica, Engenharia Civil, Engenharia Elétrica e Sistemas de Potência, Engenharia Eletrônica e Sistemas, Engenharia Mecânica, Engenharia de Minas, Engenharia Nuclear, Engenharia de Produção, Engenharia Química, Geologia Ciência da Computação e Engenharia da Computação) da referida universidade;

b) Caso seja egresso, ter concluído o curso entre 2005 e 2006;

c) Possuir a intenção de ter seu próprio negócio

O processo de identificação, triagem e escolha dos entrevistados contou inicialmente com o auxílio dos coordenadores de cada um dos cursos de base tecnológica. Por meio deles tivemos acesso a listagem dos alunos concluintes ou egressos, cujos perfis atendiam aos critérios mencionados acima. Com base nessa lista, extraímos (através de procedimento de caráter amostral e por conveniência) os indivíduos que compuseram a amostra do estudo.

Seguindo as recomendações propostas por Miles e Hubermann (1994) utilizamos o critério de saturação das respostas das entrevistas, para determinar o número total de entrevistas a serem realizadas nesse estudo. De acordo com esse critério, a coleta de dados em pesquisas qualitativas deve parar no momento em que: os discursos dos indivíduos não constituam contribuições adicionais significativas para as análises de dados e reflexões do estudo. Com base nisso, decidimos depois de realizadas 07 entrevistas (sendo 04 com alunos concluintes e 03 com egressos), que não era mais necessário continuarmos entrevistando.

No que tange ao procedimento de coleta de dados, iniciamos a entrevista propriamente dita com a seguinte pergunta de pesquisa básica: Qual é (ou foi) o significado da (ou de uma eventual) abertura de um negócio próprio em sua vida? Além desta, nos diálogos surgiram outras questões reflexivas decorrente dessa inicial, tais como: Você tem pretensão de abrir um negócio próprio? Em que área? Você acredita que o empreendedor, na sociedade, desfruta de prestígio, sendo visto com respeito e admiração?_Estas perguntas, geradas subseqüentemente, dentre outras, permitiram um conhecimento aprofundado do fenômeno investigado.

O plano analítico compreendeu uma análise de conteúdo com processo de transcrição dos relatos dos entrevistados, codificação dos conteúdos e interpretação de seus significados (MALHOTRA, 2001). Tal metodologia é compreendida como um conjunto de técnicas de análise das comunicações, focada numa investigação através de uma descrição objetiva, 
sistemática e quantitativa do conteúdo manifesto, com a finalidade da interpretação da mensagem. Assim, houve a mensuração dos fatores que influenciam tais estudantes a querer possuir seu empreendimento, sob a perspectiva das âncoras de carreira. As categorias de análise foram definidas com base no referencial teórico apresentado, sobretudo, a partir do modelo das Âncoras de Carreira (SCHEIN, 1978), uma vez que este constitui uma visão teoricamente rica para o tema do empreendedorismo.

Desta forma, a partir do mapa de codificação que foi gerado, as entrevistas realizadas foram analisadas, sendo que cada trecho representativo dos fatores que exercem influências na intenção do grupo de alunos pesquisados, recebeu um código de acordo com a adequação à determinada categoria (podendo uma frase obter mais de um código). As âncoras de carreira que foram percebidas como conceitualmente superpostas, suscitaram a necessidade de alterações de ordem contextual e conceitual. Algumas delas foram reclassificadas, a ponto de novas configurações serem realizadas, chegando-se, em alguns casos, a um terceiro nível de códigos. De fato, o mapa de âncoras de carreira ficou com a seguinte configuração: 1) Intenções Empreendedoras: Integrantes das intenções empreendedoras (Necessidade, Valor, Vontade, Hábito, Crença, Desafios, Ambição, Interesse e Satisfação) e Fatores que influenciam as intenções empreendedoras (Fatores Motivacionais e Fatores Situacionais; 2)Âncoras de Carreira: Âncora de segurança (Estabilidade financeira e Conformidade), Âncora de autonomia (Autonomia e Libertação), Âncora técnica (Especificidade e Detalhamento), Âncora de criatividade (Criatividade, Inovação e, Proatividade) e Âncora gerencial (Planejar, Controlar, Coordenar e Organizar). Vale salientar que em termos de conteúdos todas as categorias tiveram modificações. No decorrer das análises, se um trecho representativo não se adequasse às categorias pré-estabelecidas, este seria classificado como não categorizado, para posteriormente ser analisado e possivelmente codificado. Os novos códigos foram então inseridos no mapa de codificação de forma a adequá-los aos principais conceitos já abordados no referencial teórico.

\section{RESULTADOS}

$\mathrm{Na}$ presente seção, os resultados serão apresentados, recorrendo-se as Tabelas 1 e 2 que resume os elementos identificados através do mapa de codificação, como também através das análises feitas tendo as mesmas como fonte, visando, desta forma, ao aprofundamento do tema proposto na pesquisa, e ressaltando as análises necessárias para o enriquecimento desse estudo.

Compreender as intenções de empreender é crucial para o entendimento de todo o processo empreendedor, por servirem como condutor inicial para ações e eventos subseqüentes relacionados com a abertura de novos negócios. Correspondem a um "estado de espírito" que direciona a atenção, experiência e ação de um indivíduo na direção do objetivo de fundar um negócio, bem como abrangem o comprometimento deste indivíduo com a abertura deste novo negócio. Conforme Tabela 1, a área de competência de Integrantes das Intenções Empreendedoras emerge como mais importante, reforçando a idéia de que são as necessidades, valores, vontades, hábitos e crenças pessoais do (futuro) empreendedor que o incentivam a querer possuir um negócio, e não fatores exógenos a esse sujeito. 


\begin{tabular}{|c|c|c|c|}
\hline Cód. & Conceito & Freq. & $\%$ \\
\hline 1 & INTENÇÕES EMPREENDEDORAS & 159 & 100 \\
\hline 1.1 & Integrantes das intenções empreendedoras & 142 & 89,31 \\
\hline 1.1 .1 & Necessidade & 14 & $\mathbf{8 , 8 1}$ \\
\hline 1.1.2 & Valor & 25 & 15,72 \\
\hline 1.1 .3 & Vontade & 28 & 17,61 \\
\hline 1.1.4 & Hábito & 03 & 1,89 \\
\hline 1.1 .5 & Crença & 21 & 13,21 \\
\hline 1.1.6 & Desafios & 13 & 8,18 \\
\hline 1.1 .7 & Ambição & 05 & 3,14 \\
\hline 1.1 .8 & Interesse & 27 & 16,98 \\
\hline 1.1 .9 & Satisfação & $\overline{06}$ & $\mathbf{3 , 7 7}$ \\
\hline
\end{tabular}

Fonte: Dados da pesquisa processados no SPSS 11

Dentre os Integrantes das Intenções Empreendedoras investigados, que de certa forma abrangeram o comprometimento de cada sujeito com a possível abertura de seu (novo) negócio, o elemento considerado de maior relevância e poder explicativo identificado foi a Vontade. Isto demonstra que a intenção dos estudantes em possuir seu empreendimento tem por base o querer e a escolha livre, impulsionados pelo desejo de ter aquilo como suas carreiras. Eles são conduzidos a realizar aquilo que se propuseram, a atingir seus fins ou desejos, fantasias, interesses, tendo como ponto de partida a sua própria o desejo de realizar seus sonhos. Outro elemento bastante explicativo do ato de intenção de empreender é o Interesse. Esses sujeitos tendem a se interessar por empreendimento que percebem como importantes para suas vidas (pessoal ou profissional), sendo dignos de atenção àqueles que são: úteis ou vantajosos, moral, social ou materialmente benéficos, que despertam a curiosidade, o desejo de continuar a fazer.

Atrelado aos Interesses está o significado de Valor, evidenciando que os traços culturais e ideológicos que um indivíduo possui são refletidos diretamente sob o desejo de querer algo pra si. Ao tomar uma decisão, o sujeito demonstra a importância que "aquilo" representa para ele, baseado nos seus princípios (sejam pessoais ou profissionais). Só tem valor "aquilo" que possua coerência interna com sua moral. A Crença é um dos integrantes investigados na intenção de empreender que obteve destaque. Os estudantes ao intentarem empreender possuem um forte desejo em persistir naquilo em que acham ter encontrado uma verdade. Eles são propensos a persistir em suas escolhas porque acreditam ter achado nelas subsídios considerados verídicos para sua decisão e carreira a ser seguida. As Necessidades apresentam-se como desejos de querer possuir um negócio para a sua própria administração e controle, e tornar disto o seu meio de vida. Então, o Desejo, por ser uma aspiração humana de preencher um sentimento de falta e até mesmo a vontade saciar algo, manifesta-se nesses futuros empreendedores das seguintes formas: ficar rico, trabalhar em uma grande empresa para adquirir know-how, ter estabilidade financeira, conseguir sua empresa, realizar um sonho pessoal, construir família por meio do negócio, ter um lar tranqüilo e, sobretudo, qualidade de vida.

Como os estudantes ainda não iniciaram suas atividades empreendedoras, ou estão no inicio das mesmas, Satisfação, Desafios, Ambição e Hábitos foram fatores que apresentaram que emergiram, porém não possuíram extrema relevância nesse estudo. A satisfação não foi relevante, pois os mesmos estão em fase de busca por seu "contentamento", do prazer advindo da realização do que se espera, do que se deseja. Isto influencia diretamente na intenção de empreender pelo fato de se tornar um desafio a ser ultrapassado, onde suas capacidades são colocadas em jogo, a fim de atingir um estado emocional e moralmente estáveis e 
consideravelmente saciáveis. O fator ambição não foi um aspecto relevante nos profissionais investigados, uma vez que a busca veemente de alcançar determinado objetivo e também de obter sucesso em suas carreiras não estava vinculado a condições exageradas e nem a pretensões com ânsia de riquezas. Embora isso se tratasse de uma situação que envolvesse aspectos econômicos - que é a abertura de um negócio como opção de carreira e vida. Quanto aos hábitos, não exerceram praticamente influência alguma na intenção de empreender nesses estudantes, embora se saiba que as formas freqüentes, regulares ou esperadas de agir, sentir e comportar-se de um indivíduo o levam a tomada de decisões já esperadas, mas que não foi o caso em análise.

Foi mencionado no referencial teórico que as âncoras de carreira evoluem por intermédio de um processo de desenvolvimento de carreira, que envolve testar o próprio indivíduo em vários tipos de ambientes e atividades de trabalho, até que se tenha uma noção mais clara dos próprios talentos, necessidades e valores. É com base nisto que a análise das âncoras foi realizada. Conforme Tabela 2, a âncora mais relevante para compreender as intenções de empreender dos estudantes é a gerencial.

Tabela 2 - Âncoras de Carreia

\begin{tabular}{clcc} 
Cód. & Conceito & Freq. & $\%$ \\
\hline 2 & ÂNCORAS DE CARREIRA & 51 & 100 \\
2.1 & Âncora de segurança & 08 & 15,69 \\
\hline 2.2 & Âncora de autonomia & 09 & 17,65 \\
2.3 & Âncora técnica & 07 & 13,73 \\
\hline 2.4 & Âncora de criatividade & 07 & 13,73 \\
2.5 & Âncora gerencial & 20 & 39,22 \\
\hline
\end{tabular}

Fonte: Dados da pesquisa processados no SPSS 11

As questões relacionadas com o gerir do negócio (questões administrativas), bem como as competências analíticas (que os habilitam a identificar, analisar e resolver problemas sob condições de informação incompleta e incerteza), apresentam-se como a mola mestra que os direciona ao ato de empreender. Todavia, tal achado é preocupante, pois empreendedores regidos por essa âncora, sentem-se tão responsivos às exigências do trabalho, a ponto de relegarem ao segundo plano as responsabilidades técnicas, de inovação e autonomia, para buscarem segurança no emprego por meio de seguir "cegamente" os dogmas das responsabilidades gerenciais. Sendo assim, por visarem essa seguridade do dia-a-dia previamente planejada e controlada, eles não são autônomos ou independentes as normas da organização em que atuam. Isso é um fator inibidor de sua capacidade de criação e inovação, o que dificulta sua potencialidade de criar "coisas novas". Mesmo quando pretendem criar, eles têm dificuldade, pois também colocaram a margem suas responsabilidades técnicas. Realizam isso, pois preferem seu ambiente pré-moldado, a arriscar-se em um novo projeto ou empreendimento, ou seja, são avessos ao risco.

Nesse sentido, as intenções empreendedoras relacionadas acima não têm haver com o ato de empreender em si, mas, como são regidos pela égide da âncora gerencial, os estudantes não parecem ser empreendedores, mas sim, gestores de empresas. O que nos leva a refletir se as formações empreendedoras que esses jovens estão recebendo nas Universidades, realmente os socializam para serem empreendedores. 


\section{CONCLUSÕES}

Conforme pode ser constatado, os estudantes têm intenção de empreender, de possuir o próprio empreendimento tendo por base o desejo de ter aquilo como suas respectivas carreiras. Tal fato pode ser constatado na saliência dos seguintes elementos Vontade, Interesse e Valor. Assim, os futuros empreendedores são conduzidos a realizar aquilo que se propuseram, a atingir seus fins ou desejos, fantasias, interesses, embasados no querer um negócio seu. Através de seus interesses observa-se o anseio pelo investir cada vez mais para a valorização de suas aptidões, através de cursos, capacitações, sendo evidente o envolvimento com atividades que possibilitem o desenvolvimento intelectual em assuntos que de fato consideram importante moral, social ou materialmente, com vias a alavancar seu potencial empreendedor. Todavia, apesar da intenção de empreender, os estudantes não apresentaram as âncoras de carreiras necessárias para o agir empreendedor, a saber: criatividade e autonomia. De fato, por serem fortemente influenciados pela ancora gerencial, os estudantes tenderão a se fixarem em determinada organização, sendo seus esforços voltados para manterem seus empregos, bem como galgarem novos postos nela. Com base nesse estudo, podemos questionar até que ponto o processo de ensino/aprendizagem - assim como, o de socialização - empreendedor realizado pelas universidades realmente fomentam o florescer da cultura do empreendedorismo no Brasil. Assim, é importante continuar pesquisando, qual(is) as vontades que induzem as pessoas empreenderem.

\section{Referências}

AJZEN, I. Attitudes, traits and actions: dispositional prediction of behavior in personality and social psychology. In: BERKOWITZ, L. (Ed.), Advances in Experimental and Social Psychology. San Diego: Academic Press, 1987.

AJZEN, I. From intentions to actions: a theory of planned behavior. In: KUHL, J., BECKMANN, J. (Eds.), Action-Control: From Cognition to Behavior. Heidelberg: Springer, pp. 11-39, 1985.

ALLEN, T.J.; KATZ, R. The dual ladder: motivational solution or managerial delusion? R\&D Management, Vol. 16, pp. 185-197, 1986.

BARTH, T. J. Career anchor theory. Review of Public Personnel Administration, Vol. 13, pp. 27-42, 1993.

BECKER, G. S. Human Capital. New York: National Bureau for Economic Research, 1964.

BIRD, B. Implementing entrepreneurial ideas: the case for intention. Academy of Management Review, 1988.

BIRD, B. J. The operation of intentions in time: the emergence of the new venture. Entrepreneurship Theory and Practice, v. 17, p. 11-20, 1992.

BOYD, N. G.; VOZIKIS, G. S. The influence of self-efficacy on the development of entrepreneurial intentions and actions. Entrepreneurship Theory and Practice, v. 18, p. 63-77, 1994.

CHANLAT, Jean-François. Quais carreiras para qual sociedade? Revista de Administração de Empresa, São Paulo, v. 35, n. 6, p. 67-75, 1995. 
CRANT, J. M. The proactive personality scale as a predictor of entrepreneurial intentions. Journal of Small Business Management, v. 34, p. 42-49, 1996.

CROMIE, S. Entrepreneurship: the role of the individual in small business development. Irish Journal of Business and Administrative Research, v. 15, p. 62-73, 1994.

DRUCKER, P. F. Inovação e espírito empreendedor: prática e princípios. São Paulo: Pioneira, 1987.

DUBINI, P. The influence of motivations and environment on business start-ups: some hints for public policies. Journal of Business Venturing, v. 4, p. 11-26, 1988.

DYER JR., W. G. The Entrepreneurial Experience. San Francisco: Jossey-Bass, 1992.

DYER JR., W. G. Toward a theory of entrepreneurial careers. Entrepreneurship Theory and Practice, 1994.

FELDMAN, D. C.; BOLINO, M. C. Career patterns of the self-employed: career motivations and career outcomes. Journal of Small Business Management, v. 38, p. 53-67, 2000.

FILION, L. J. Diferenças entre sistemas gerenciais de empreendedores e operadores de pequenos negócios. Revista de Administração de Empresas, São Paulo, v. 39, n. 4, p. 6-20, 1999.

FISHBEIN, M.; AJZEN, I. Belief, Attitude, Intention and Behavior: An Introduction to Theory and Research. New York: Addison-Wesley, 1975.

GARTNER, W. B. A conceptual framework for describing the phenomenon of new venture creation. Academy of Management Review, v. 10, n. 4, p. 696-706, 1985.

GARTNER, W. B. Who is an entrepreneur? Is the wrong question. American Journal of Small Business, v. 4, n. 12, p. 11-32, 1988.

GARTNER, W. B.; MITCHELL, T. R.; VESPER, K. H. A taxonomy of new business ventures. Journal of Business Venturing, v. 4, p. 169-186, 1989.

GARTNER, W. B.; SHAVER, K. G.; GATEWOOD, E.; KATZ, J. A. Finding the entrepreneur in entrepreneurship. Entrepreneurship Theory and Practice, v. 18, n. 3, p. 5-9, 1994.

GOFFEE, R., SCASE, R. Organizational change and the corporate career: the restructuring of managers' job aspirations. Human Relations, v. 45, p. 363-385, 1992.

GREENBERGER, D. B., SEXTON, D. L. An interactive model of new venture initiation. Journal of Small Business Management, v. 23, p. 1-7, 1988.

GREENHAUS, J. H., SUGALSKI, T., CRISPIN, G. Relationships between perceptions of organizational size and the organizational choice process. Journal of Vocational Behavior, v. 13, p. 113-125, 1978.

HERRON, L., SAPIENZA, H. J. The entrepreneur and the initiation of new venture launch activities. Entrepreneurship Theory and Practice, v. 17, p. 49-55, 1992. 
HOLLENBECK, J., WHITENER, E. Reclaiming personality traits for personnel selection. Journal of Managemen, v. 14, p. 81-91, 1988.

IGBARIA, M.; GREENHAUS, J. H.; PARASURAMAN, S. Career orientations of MIS employees: an empirical analysis. Management Information Systems Quarterly, v. 15, p. 151$169,1991$.

JENKINS, M. JOHNSON, G. Entrepreneurial intentions and outcomes: a comparative causal mapping study. Journal of Management Studies, v. 34, p. 895-920, 1997.

JOHNSON, B. Toward a multidimensional model of entrepreneurship: the case of achievement motivation and the entrepreneur. Entrepreneurship Theory and Practice, v. 14, p. 39-54, 1990.

KANTER, R. M. When Giants Learn to Dance. London: Simon and Schuster, 1989.

KATZ, J. A. GARTNER, W. B. Properties of emerging organization. Academy of Management Review, v. 13, p. 429-441, 1988.

KATZ, J. A. Modeling entrepreneurial career progressions: concepts and considerations. Entrepreneurship Theory and Practice, v. 19, p. 23-39, 1994.

KETS DE VRIES, M. F. R. Organizational paradoxes: clinical approaches to management. 2.ed., Routledge, 1995.

KISFALVI, V. The entrepreneur's charcter, life issues, and strategy making: a field study. Journal of Bussiness Venturing, v. 17, n.5, p. 489-519, 2002.

KOLVEREID, L. Organizational employment versus self-employment: reasons for career choice intentions. Entrepreneurship Theory and Practice, v. 20, p. 23-31, 1996.

KRUEGER JR., N. F., BRAZEAL, D. V. Entrepreneurial potential and potential entrepreneurs. Entrepreneurship Theory and Practice, v. 18, p. 91-104, 1994.

KRUEGER JR., N. F.; BRAZEAL, D. V. Entrepreneurial potential and potential entrepreneurs. Entrepreneurship Theory and Practice, v. 18, p. 91-104, 1994.

KRUEGER, N. F.; CARSRUD, A. L. Entrepreneurial intentions: applying the theory of planned behavior. Entrepreneurship and Regional Development, v. 5, p. 315-330, 1993.

KRUEGER, N. The impact of prior entrepreneurial exposure on perceptions of new venture feasibility and desirability. Entrepreneurship Theory and Practice, v. 18, n. 1, p. 5-21, 1993.

LEARNED, K. E. What happened before the organization? A model of organization formation. Entrepreneurship Theory and Practice, v. 17, p. 39-48, 1992.

LEITE, M. P.; RIZEK , C. S. Cadeias, complexos e qualificações. In: LEITE, M. P.; NEVES, M. A. Trabalho, qualificação e formação profissional. São Paulo: ALAST, p. 45-76, 1999.

MALHOTRA, N. K. Pesquisa de marketing. Porto Alegre: Bookman, 2001. 
MERRIAN, S. B. Qualitative research and case study applications in education: revised and expanded from case study research in education. 1998.

MILES, M. B.; HUBERMAN, A. M. Qualitative data analysis: an expanded source book. 2.ed., Sage, 1994.

NICHOLSON, N., WEST, M. Managerial Job Change: Men and Women in Transition. Cambridge: Cambridge University Press, 1988.

PHILIPSEN, K. Entreprenurship as organizing: a literature study of entrepreneurship. DRUID, Summer. Conference proceedings. Bornholm, Dinamarca, 1998.

POCHMANN, M. O emprego na globalização. São Paulo: Biotempo Editorial, 2001.

PREVIDELLI, J. J.; MEURER, V.; PREVIDELLI, I. T. S. Estudo da causa mortis de micros e pequenas empresas brasileiras. Ciudad de México, México: XXXVI Asamblea Anual del Cladea, 2001.

REYNOLDS, P. D. Sociology and entrepreneurship: concepts and contributions. Entrepreneurship Theory and Practice, v. 16, p. 47-70, 1991.

RTNER, W. B.; BIRD, B. J.; STARR, J. A. Acting as if: differentiating entrepreneurial from organizational behavior. Entrepreneurship Theory and Practice, 1992.

SCHEIN, E. H. Career anchors revisited: implications for career development in the 21st century. Academy of Management Executives, v. 10, p. 80-88, 1996.

SCHEIN, E. H. Career Anchors: Discovering Your Real Values. San Diego, CA: University Associates, 1990.

SCHEIN, E. H. Career Dynamics: Matching Individual and Organizational Needs. Reading, MA: Addison-Wesley Publishing, 1978.

SCHEINBERG, S.; MACMILLAN, I. C. An 11 country study of motivations to start a business. In: KIRCHHOFF, B.A., LONG, W.A., MCMULLAN, W.E.,1988 VESPER, K.H., WETZEL JR., W.E. (Eds.). Frontiers of Entrepreneurship Research, p. 337-356, 1988.

SMILOR, R. W. Entrepreneurship Reflections on a Subversive Activity. Journal of Business Venturing, v. 12, p. 341-346, 1997.

SMITH, N. R.; MINER, J. B. Type of entrepreneur, type of firm, and managerial innovation: implications for organizational life cycle theory. In: Hornaday, J. A., Timmons, J., Vesper, K. (Eds.), Frontiers of Entrepreneurship Research, p. 51-71, 1983.

STEWART JR., W. H.; WATSON, W. E.; CARLAND, J. C.; CARLAND, J. W. A proclivity for entrepreneurship: a comparison of entrepreneurs, small business owners, and corporate managers. Journal of Business Venturing, v. 14, p. 189-214, 1998.

VESPER, K.H. New Venture Strategies. Englewood Cliffs, NJ: Prentice-Hall, 1980;

WOO, C. Y.; COOPER, A.; DUNKELBERG, W. C. The development and interpretation of entrepreneurial typologies. Journal of Business Venturing, v. 6, p. 94-114, 1991. 